\title{
BMJ Open Rhinothermy delivered by nasal high flow therapy in the treatment of the common cold: a randomised controlled trial
}

\author{
Grace Bird (D , , Irene Braithwaite (D) , ${ }^{1}$ James Harper, ${ }^{1}$ Iris Koorevaar, ${ }^{1}$ \\ Marthe van den Berg, ${ }^{1}$ Ingrid Maijers, ${ }^{1}$ Nethmi Kearns (D) , ${ }^{1}$ Meik Dilcher, ${ }^{2}$ \\ Lance Jennings, ${ }^{2}$ James Fingleton, ${ }^{1}$ Nick Shortt, ${ }^{1}$ Mark Weatherall, ${ }^{3}$ \\ Richard Beasley (iD ${ }^{1}$
}

To cite: Bird G, Braithwaite I, Harper J, et al. Rhinothermy delivered by nasal high flow therapy in the treatment of the common cold: a randomised controlled trial. BMJ Open 2021;11:e047760. doi:10.1136/ bmjopen-2020-047760

- Prepublication history and additional supplemental material for this paper are available online. To view these files, please visit the journal online (http://dx.doi.org/10.1136/ bmjopen-2020-047760).

Received 08 December 2020 Accepted 01 November 2021

Check for updates

(C) Author(s) (or their employer(s)) 2021. Re-use permitted under CC BY-NC. No commercial re-use. See rights and permissions. Published by BMJ.

${ }^{1}$ Medical Research Institute of New Zealand, Wellington, New Zealand

${ }^{2}$ Canterbury Health Laboratories, Christchurch, New Zealand

${ }^{3}$ University of Otago Wellington, Wellington, New Zealand

Correspondence to

Dr Grace Bird;

grace.bird@mrinz.ac.nz

\section{ABSTRACT}

Background The common cold is the most common infectious disease affecting humans and has a substantial economic impact on society. Human rhinoviruses, which cause almost two-thirds of colds, have demonstrated temperature-dependent replication which is optimal between $33^{\circ} \mathrm{C}$ and $35^{\circ} \mathrm{C}$.

Methods This randomised, single-blind, parallel-group trial completed at a single-centre in New Zealand, recruited 170 participants aged $18-75$ years (mean age 27.5 years) who were within 48 hours of common cold symptom onset and had a symptom score (the Modified Jackson Score (MJS)) $\geq 7$ and a negative pointof-care test for influenza. Participants were blinded to the intervention and randomised $(1: 1)$ to 5 days of either nasal high flow rhinothermy (rNHF) (100\% humidified air delivered at $35 \mathrm{~L} / \mathrm{min}$ and $41^{\circ} \mathrm{C}$ for 2 hours daily) $(n=85)$ or 'sham' rhinothermy ( $100 \%$ humidified air delivered at $10 \mathrm{~L} / \mathrm{min}$ and $31^{\circ} \mathrm{C}$ for $10 \mathrm{~min}$ daily) $(\mathrm{n}=85)$ and completed daily symptom diaries, which included the MJS, for 14 days, to investigate whether rNHF reduced common cold symptom severity and duration compared with 'sham' rhinothermy.

Results An intention-to-treat superiority analysis included all randomised participants and showed no difference between treatment groups for the primary outcome, the day 4 MJS analysed by analysis of covariance: mean (SD) 6.33 (3.97) for rNHF vs 5.8 (3.15) for 'sham'; estimated difference $(95 \% \mathrm{Cl}) 0.37(-0.69$ to 1.42$), p=0.49$. There was no difference in time until resolution of symptoms: mean (SD) 5.96 (4.47) days for rNHF vs 6.42 (4.09) days for 'sham'; estimated difference $(95 \% \mathrm{Cl}) 1.02(0.75$ to 1.38), $p=0.91$. There were no serious adverse events related to the study treatments.

Conclusions This well-powered, single-blind randomised controlled trial does not provide evidence that 5 days of rNHF $\left(100 \%\right.$ humidified air heated to $41^{\circ} \mathrm{C}$ delivered at $35 \mathrm{~L} / \mathrm{min}$ for 2 hours daily) reduces common cold symptom severity or duration. However, investigation of rNHF in the treatment of influenza is warranted.

Trial registration number ACTRN12617001340325.
Strengths and limitations of this study

- Investigator supervised first treatment which ensured the first dose was received.

- Use of a sham intervention reduces any potential device-related effect.

- Due to the nature of the intervention it was not possible to use a double-blind design.

- Limited accuracy of adherence data as only available from download of device use data. The sample population consists of predominantly university students which reduces the overall generalisability of the results.

\section{INTRODUCTION}

The common cold is the most common infectious disease affecting humans. ${ }^{1}$ It can cause significant morbidity and is a major cause of exacerbations of asthma and chronic obstructive pulmonary disease (COPD).$^{23}$ Furthermore, it has a substantial economic impact on society. In the USA alone, non-influenza viral respiratory tract infections cause an estimated 20 million lost workdays, 110 million physician visits and 6 million emergency department visits annually, ${ }^{4}$ producing an economic burden of US $\$ 40$ billion each year. ${ }^{4}$ There are many cold remedies marketed, however, the evidence for their effectiveness is inconclusive or, at most, demonstrates limited symptom reduction. ${ }^{5}$

Human rhinoviruses (HRVs) cause up to two-thirds of colds and have temperaturedependent replication. ${ }^{6}$ In vitro replication of most HRV strains is optimal between $33^{\circ} \mathrm{C}$ and $35^{\circ} \mathrm{C}^{6},{ }^{6}$ which is the normal physiological temperature of the upper airways, ${ }^{6}$ whereas temperatures of $39^{\circ} \mathrm{C}-45^{\circ} \mathrm{C}$ have been demonstrated to inhibit viral replication. ${ }^{7-10}$ In addition, local hyperthermia may 
enhance antiviral activity, ${ }^{11}{ }^{12}$ and heated humidified air (HHA) has been shown to reduce nasal congestion and secretions in allergic rhinitis. ${ }^{13}$ These observations raise the possibility that rhinothermy, a treatment which increases upper airway temperature by delivering HHA via the nares, may attenuate the severity and duration of common cold symptoms.

A Cochrane systematic review identified six studies in which participants with the common cold were treated with HHA, and reported no evidence of harm or benefit. ${ }^{1}$ However, the evidence quality was low grade, ${ }^{1}$ and the studies used a variety of delivery systems which may have been inefficient and inconsistent in their delivery of HHA to the upper airways. ${ }^{74-17}$ These limitations are potentially overcome with the use of a nasal high flow (NHF) device which can deliver gas at a consistent temperature with minimal entrainment of ambient air.

In a proof-of-concept feasibility randomised controlled trial (RCT), 5 days of NHF rhinothermy (rNHF), which delivered $100 \%$ humidified air at $35 \mathrm{~L} / \mathrm{min}$ and $41^{\circ} \mathrm{C}$ for 2 hours daily to participants with common cold symptoms, achieved a clinically significant reduction in symptom score compared with vitamin $\mathrm{C}$ treatment. ${ }^{18}$

Subsequently, we have undertaken a well-powered RCT to investigate the effectiveness of rNHF in the treatment of the common cold. We hypothesised that rNHF would reduce symptom severity and duration compared with ‘sham' rhinothermy.

\section{METHODS}

\section{Study design and participants}

This study was a randomised, single-blind, parallel-group trial that compared 5 days of rNHF with 'sham' rhinothermy in the treatment of the common cold.

The study was completed at a single site in Wellington, New Zealand (the Medical Research Institute of New Zealand (MRINZ)) in accordance with Good Clinical Practice guidelines and the Declaration of Helsinki. The protocol was prospectively registered and published. ${ }^{19}$ The study was advertised within the local hospital, universities, general practices and the MRINZ social media feed and website. Advertisements included contact details for the principal investigator who then arranged a screening visit and sent a study-specific information sheet to those who volunteered as potential participants. All potential participants provided informed consent prior to proceeding with the screening visit which was conducted by study investigators. Eligible participants were adults aged 18-75 years presenting within 48 hours of self-reported onset of common cold symptoms, with a Modified Jackson Score (MJS) ${ }^{20} 21 \geq 7$ (figure 1). The MJS is a validated symptom severity score for viral upper respiratory tract infection (URTI). The study was conducted alongside a related trial for participants with influenza which used both this study protocol and its own separate protocol. Further details for this trial are not included in this paper.

$\begin{array}{lcccc} & \text { Absent } & \text { Mild } & \text { Moderate } & \text { Severe } \\ \text { Nasal congestion } & 0 & 1 & 2 & 3 \\ \text { Nasal discharge } & 0 & 1 & 2 & 3 \\ \text { Sneezing } & 0 & 1 & 2 & 3 \\ \text { Sore/scratchy throat } & 0 & 1 & 2 & 3 \\ \text { Cough } & 0 & 1 & 2 & 3 \\ \text { Headache } & 0 & 1 & 2 & 3 \\ \text { Malaise } & 0 & 1 & 2 & 3 \\ \text { Fever/chills } & 0 & 1 & 2 & 3\end{array}$

Figure 1 The Modified Jackson Score (MJS). The MJS is a validated symptom severity score for upper respiratory tract infection. Individuals rate eight characteristic common cold symptoms as either absent, mild, moderate or severe to produce a total score out of 24. An MJS of greater than or equal to seven was an inclusion criterion for this study.

\section{Exclusion criteria}

A history of an immunocompromising condition, notifiable disease, COPD or other significant respiratory conditions, or nasal conditions which could impair nasal breathing (such as a deviated nasal septum or chronic rhinosinusitis); a current diagnosis of asthma with symptoms or requirement of asthma medication during the last 12 months; current use of or requirement for oral antibiotics for respiratory tract infection, pneumonia or infective exacerbation of underlying respiratory condition; current use of or requirement for parenteral antibiotics; presence of an implantable medical device; a positive GeneXpert point-of-care test for influenza A or $\mathrm{B}$; pre-existing travel plans that require them to leave the greater Wellington region during the first 5 days of the study.

\section{Treatment, randomisation and masking}

Following the screening process, enrolled participants were randomised 1:1 to receive 5 days of $\mathrm{rNHF}(100 \%$ humidified air delivered at $35 \mathrm{~L} / \mathrm{min}$ and $41^{\circ} \mathrm{C}$ for 2 hours daily) or 'sham' rhinothermy ( $100 \%$ humidified air delivered at $10 \mathrm{~L} / \mathrm{min}$ and $31^{\circ} \mathrm{C}$ for $10 \mathrm{~min}$ daily).

The 'sham' settings were chosen to produce a treatment which would control for device effect, but also minimise any potential therapeutic effect. Low airflow rates maximise entrainment of ambient air, therefore, $31^{\circ} \mathrm{C}$ at $10 \mathrm{~L} / \mathrm{min}$ was unlikely to bring nasopharyngeal temperature outside the usual physiological range.

A permuted block randomisation method stratified by duration of illness, $<24$ hours vs $\geq 24$ hours, was used to allocate participants to either treatment. An independent study statistician supplied the computer-generated sequence. The randomisation schedule was only accessed by the study statistician and data management team. The electronic case report form (eCRF) system concealed the allocations and released them at the time of randomisation.

Study investigators screened and enrolled participants and were unmasked to treatment allocation. Both treatments used a device that delivered HHA to the airways 
via a nasal cannula. Participants were informed that two different rhinothermy regimens were being investigated but did not know which regimen was the investigational treatment, nor details of either regimen. As such, all participants were masked to their treatment.

\section{Procedures}

All study visits took place at MRINZ. The screening visit included calculation of symptom duration and day 1 (baseline) MJS, and collection of nasopharyngeal specimens which were tested for the presence of influenza type A or B. Samples from enrolled participants were sent for multiplex respiratory testing.

Immediately following screening, enrolled participants were randomised to their treatment and received instruction in its use. On day 1, the first treatment was administered under the supervision of investigators. On days 2-5, participants self-administered their treatment at home.

Those randomised to rNHF were encouraged to administer their treatment in a single 2-hour session. However, if they were unable to do so, they were advised that treatment could be split into no more than two sessions aiming for a total of 2 hours of rhinothermy on each treatment day. Participants were also permitted to reduce the flow rate from $35 \mathrm{~L} / \mathrm{min}$ to $30 \mathrm{~L} / \mathrm{min}$ according to comfort. Those randomised to 'sham' were encouraged to administer their treatment in a single 10 min session and were unable to adjust the flow rate.

Participants were asked to complete a daily symptom diary (figure 2) on day 2 until day 14 inclusive. Using the symptom diary, participants were asked to document the daily MJS; how they felt each day as compared with day 1 , either a lot worse, a little worse, about the same, a little better, or a lot better; if they had returned to their normal daily activities; and details regarding use

\section{Jackson Score Diary}

\begin{tabular}{|c|c|c|c|c|}
\hline & Absent & Mild & Moderate & Severe \\
\hline Nasal congestion & $\circ$ & ○ & ○ & ० \\
\hline Nasal discharge & ० & o & ○ & $\circ$ \\
\hline Sneezing & ○ & ○ & ○ & ○ \\
\hline $\begin{array}{l}\text { Sore/scratchy } \\
\text { throat }\end{array}$ & o & o & o & $\circ$ \\
\hline Cough & $\circ$ & ○ & $\circ$ & $\circ$ \\
\hline Headache & ○ & ○ & ○ & o \\
\hline Malaise & ○ & o & ○ & ○ \\
\hline Fever/chills & $\circ$ & ○ & ○ & $\circ$ \\
\hline
\end{tabular}

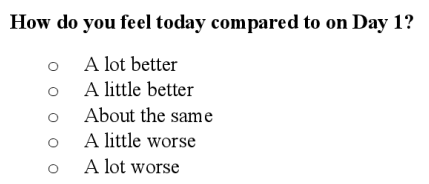

Have you returned to your normal daily activities today? Yes No

Figure 2 Daily symptom diary. An example of the daily symptom diary completed by participants on day $2-14$ of the study. of any medications or remedies for symptoms. Enrolled participants were asked to refrain from using any overthe-counter medication or remedies for symptom relief for the duration of the study, however, their use did not constitute a reason for withdrawal.

Participants were asked to visit the MRINZ on day 5 to return their devices and complete a tolerability questionnaire regarding their device and treatment. Any new medications, adverse events (AEs) or device issues were also reviewed during this visit and again during the day 14 follow-up phone call. Both treatment devices automatically recorded device use data electronically which study investigators downloaded on return from each participant.

\section{Nasopharyngeal specimen handling and testing}

Nasopharyngeal specimens were obtained using Copan's flocked swabs (FLOQSwab). These specimens were tested for the presence of influenza type A or B virus nucleic acid using the GeneXpert Xpress influenza/respiratory syncytial virus (RSV) point-of-care test (Cepheid, Sunnyvale, California, USA). The sensitivity and specificity of real-time PCR using the GeneXpert Xpress influenza/ RSV point-of-care test for the rapid diagnosis of influenza virus has been reported as $97.8 \%$ and $100 \%$, respectively. ${ }^{22}$

Nasopharyngeal specimens obtained from enrolled participants were also sent to Canterbury Health Laboratories for multiplex respiratory testing using Fast Track Diagnostic (FTD) Respiratory pathogens 21 assay, to confirm the presence or absence of 21 different respiratory pathogens: influenza A virus; influenza A (H1N1) pdm 2009 virus; influenza B virus; HRV; human coronavirus (CoV) NL63, 229E, OC43 and HKU1; human parainfluenza virus 1, 2, 3, and 4 (PIV1, PIV2, PIV3, PIV4); human metapneumovirus A/B; human bocavirus; human RSV A/B; human adenovirus; enterovirus; human parechovirus and Mycoplasma pneumoniae.

Both enterovirus and HRV are from the picornaviridae family and there is high sequence homology between the two. This can result in the detection of both HRV and enterovirus using the respiratory 21 assay. Due to this cross-reactivity, enterovirus and HRV cannot be reliably differentiated and may mimic coinfection.

\section{Data collection}

Study data were collected and managed using Research Electronic Data Capture (REDCap) tools hosted at MRINZ. ${ }^{23}$ REDCap is a secure, web-based software platform designed to support data capture for research studies, providing an intuitive interface for validated data capture; audit trails for tracking data manipulation and export procedures; automated export procedures for seamless data downloads to common statistical packages; and procedures for data integration and interoperability with external sources.

Study visits took place on day 1 and day 5, with a follow-up phone call on day 14 . The MJS on day 1 was collected by the investigator as part of the screening visit. 
After this, participants completed a daily symptom diary (figure 2) remotely and entered this data directly into either an eCRF on REDCap, or on paper.

All enrolled participants reported having home internet and email access. The links to the daily symptom diary were generated by REDCap and sent to the participants via automated email. Participants entered their online symptom diary data directly into REDCap. All participants were provided with paper versions of the daily symptom diary for use if they lost computer or internet access.

\section{Outcomes}

In the recent RCT of rNHF compared with vitamin C, the greatest difference in MJS between treatment groups was on day $4 .{ }^{18}$ The day $4 \mathrm{MJS}$ was therefore chosen as the primary outcome for this study. Secondary outcomes were daily MJS from day 2 up to day 14 inclusive; the number of days until feeling 'a little better' and 'a lot better' compared with day 1 ; the number of days until resolution of symptoms; and the number of days until 'return to normal daily activities'. Time until resolution of symptoms was used to assess the effect of treatment on duration of the common cold. Resolution of symptoms was defined as the start of a 24-hour period in which the MJS was less than or equal to oneand remained so for 24 hours. Prespecified potential effect modifying variables were HRV positive status, and duration of symptoms before randomisation: treatment $<24$ hours vs $\geq 24$ hours but $\leq 48$ hours from symptom onset.

Other outcomes were the number of participants with each pathogen type identified by PCR analysis of nasopharyngeal specimens; patterns of device use; adherence to treatment; and treatment tolerability including ease of use, overall comfort, and likelihood of future use (online supplemental appendix 1.1). Finally, in view of the current SARS-CoV-2 (COVID-19) pandemic, we performed a post hoc analysis to test for an interaction between human $\mathrm{CoV}$ status and the primary outcome.

\section{Device use and adherence}

Patterns of use of the rNHF and 'sham' rhinothermy devices, including number of minutes and treatment sessions used per day, were determined by the stored device data downloaded on day 5. Adherence to rNHF was defined as a minimum of $90 \mathrm{~min}$ of use per day, delivered in no more than two sessions per day. Adherence to 'sham' rhinothermy was defined as a minimum of $6 \mathrm{~min}$ of use per day, delivered in no more than a single session.

\section{Statistical analysis}

The statistical analysis was an intention-to-treat superiority analysis and included all randomised participants. Full analysis details in online supplemental appendix 1.2.

\section{Sample size}

A sample size of 85 in each treatment group had $90 \%$ power, alpha $5 \%$ to detect a difference in MJS of 3.5 units allowing for $10 \%$ drop-out (explanation in online supplemental appendix 1.3).
Table 1 Baseline characteristics for continuous and categorical variables

\begin{tabular}{|c|c|c|}
\hline & \multicolumn{2}{|l|}{ Mean (SD) } \\
\hline & $\mathrm{rNHF}^{*} \mathrm{~N}=85$ & Sham $+N=85$ \\
\hline Age (years) & $25.8(6.7)$ & $29.3(11.5)$ \\
\hline $\begin{array}{l}\text { Symptom duration at time } \\
\text { of randomisation (hours) }\end{array}$ & 31.1 (11.3) & $31.5(9.8)$ \\
\hline \multirow[t]{3}{*}{ Day 1 (baseline) MJS $\ddagger$} & $12.26(3.43)$ & $11.71(3.30)$ \\
\hline & \multicolumn{2}{|l|}{$\mathrm{N} / 85(\%)$} \\
\hline & rNHF & Sham \\
\hline Sex (female) & $60(70.6)$ & $62(72.9)$ \\
\hline \multicolumn{3}{|l|}{ Ethnicity } \\
\hline Asian & $8(9.4)$ & $4(4.7)$ \\
\hline European & $69(81.2)$ & $69(81.2)$ \\
\hline Maori & $6(7.1)$ & $7(8.2)$ \\
\hline Other & $1(1.2)$ & $0(0)$ \\
\hline Pacific & $1(1.2)$ & $5(5.9)$ \\
\hline \multicolumn{3}{|l|}{ Smoking status } \\
\hline Current & 7 (8.2) & $2(2.4)$ \\
\hline Ex-smoker & $10(11.8)$ & $16(18.8)$ \\
\hline Never-smoker & $68(80.0)$ & $67(78.8)$ \\
\hline
\end{tabular}

*Nasal high flow rhinothermy treatment group.

†Sham rhinothermy group.

$\ddagger$ The MJS is a validated symptom severity score for viral upper respiratory tract infection. Participants score eight symptoms from 0-absent, 1-mild, 2-moderate, 3-severe, to produce a symptom score out of 24 . The eight symptoms are nasal congestion, nasal discharge, sneezing, sore/scratchy throat, cough, headache, malaise and fever/chills.

MJS, Modified Jackson Score; rNHF, nasal high flow rhinothermy.

\section{RESULTS}

Study results have been reported in line with Consolidated Standards of Reporting Trials guidelines for parallel group randomised trials. ${ }^{24}$ All results are available in the online supplemental materials.

There were 170 participants recruited between February 2018 and July 2019. Table 1 describes the baseline characteristics of these participants in relation to randomised treatment.

Figure 3 shows the flow of participants through the trial. There were 208 potential participants who were screened for eligibility, 38 of whom were ineligible for enrolment in the study (online supplemental table 1). One participant in the rNHF group withdrew, and another in this group had their treatment discontinued on day 3 due to safety concerns.

There were $112(66 \%)$ participants PCR positive for a common cold virus, among whom the most frequent viruses were HRV (61\%) and coronaviruses (29\%) (online supplemental table 2).

The mean (SD) day 1, baseline, MJS was 12.26 (3.43) for rNHF, and 11.71 (3.30) for 'sham' (online supplemental table 3). The mean (SD) symptom duration at 


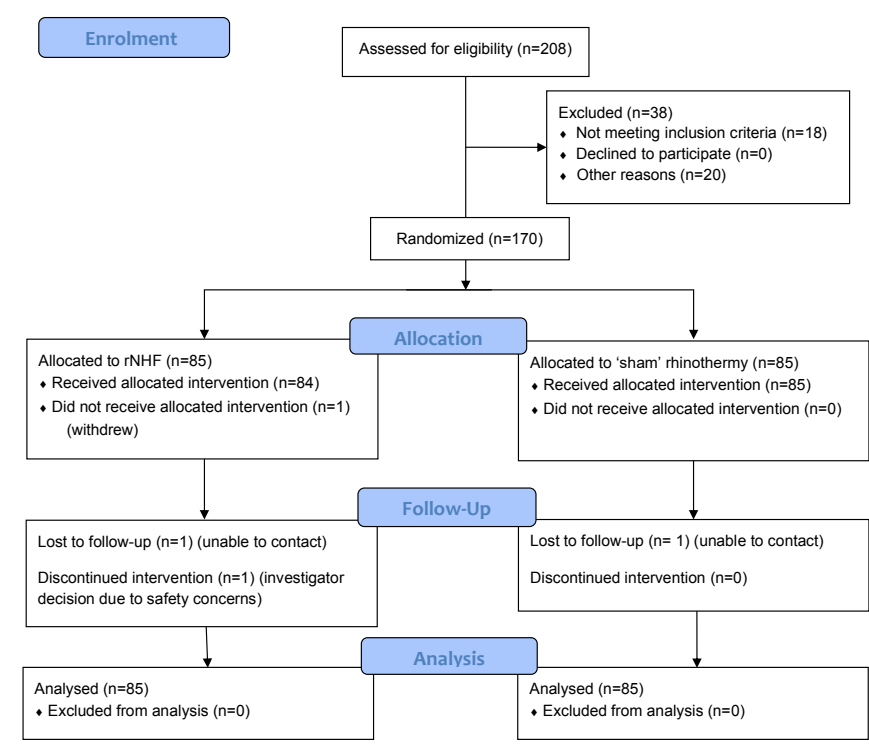

Figure 3 A flow diagram outlining participant study progress. rNHF, nasal high flow rhinothermy.

randomisation was 31.1 (11.3) hours for rNHF and 31.5 (9.8) hours for 'sham' (online supplemental table 3). All participants were within 48 hours of symptom onset at the point of randomisation, and $31(18 \%)$ were within 24 hours (online supplemental table 4).

\section{Primary outcome}

There was no difference between treatment groups for the primary outcome: mean (SD) day 4 MJS 6.33 (3.97) for rNHF vs 5.8 (3.15) for 'sham'; estimated difference $(95 \% \mathrm{CI}) \quad 0.37$ ( -0.69 to 1.42$), \mathrm{p}=0.49$ (online supplemental figure 1 and online supplemental table 5).

\section{Secondary outcomes}

There was no difference between treatment groups for MJS on any individual day (online supplemental figure 2 and online supplemental table 6). An interaction term 'time-by-treatment' was not statistically significant $(\mathrm{p}=0.72)$, therefore, there was no evidence that the difference between treatments changed at specific times (online supplemental table 6).
For the time-until-event outcome variables, there was no difference in time to feeling 'a little better' or 'a lot better', or time until 'return to normal daily activities' (online supplemental figure 3 to 5 , and online supplemental table 7a). There was no difference in time until resolution of symptoms: mean (SD) 5.96 (4.47) days for rNHF vs 6.42 (4.09) days for 'sham'; estimated difference $(95 \% \mathrm{CI}) 1.02$ (0.75 to 1.38$), \mathrm{p}=0.91$ (online supplemental figure 6 and online supplemental table $7 \mathrm{a}$ ).

\section{Interaction analyses}

There was no evidence that the difference between treatments for the primary outcome was altered by symptom duration at the time of randomisation, $p$ interaction $=0.87$ (table 2; online supplemental table 8a,b). There was some evidence that the difference between treatment groups varied depending on HRV status, $p$ interaction $=0.001$. Participants in the rNHF group with a nasopharyngeal specimen PCR positive for HRV, did worse than those in the 'sham' group. The estimated difference $(95 \% \mathrm{CI})$ for the primary outcome was 2.07 ( 0.41 to 3.73 ), $\mathrm{p}=0.015$ for HRV positive participants compared with $-0.76(-2.10$ to 0.58 ), $\mathrm{p}=0.26$, for HRV negative participants (table 2; online supplemental tables $9 \mathrm{a}, \mathrm{b}$ and online supplemental figure 7).

\section{Other outcomes}

For all seven tolerability questions, the ORs indicate that 'sham' was more likely to have a higher (more favourable) score than rNHF (online supplemental table 10i to vii). Using 'overall comfort in using the treatment device' as an indicator for tolerability, there was strong evidence that 'sham' had greater tolerability than rNHF, OR (95\% CI) 7.05 (3.66 to 13.6) $(\mathrm{p}<0.001)$. Device data and patterns for device use for each treatment group including mean device flow rate, daily treatment use (in hours), and number of treatment sessions are given in online supplemental table 3 .

There was no difference in adherence to treatment between groups, with mean (SD) adherence at $4.59(0.93)$ days for rNHF, and 4.54 (0.85) days for 'sham' (online supplemental tables 3, 11a, and 11b).

Table 2 Estimates of treatment differences in primary outcome by symptom duration, HRV status and CoV status

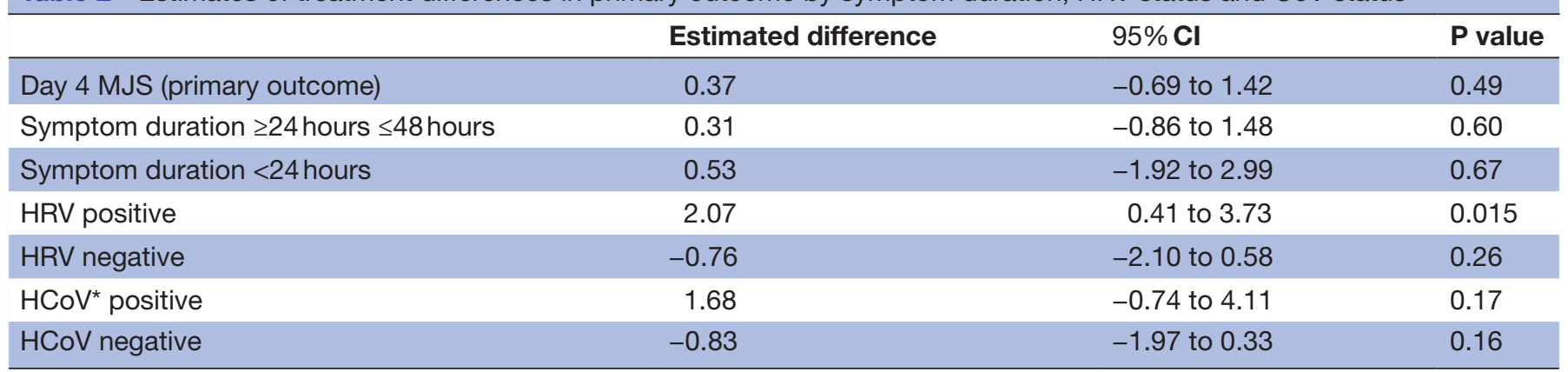

*Human coronavirus (includes HCoV-0C43, HCoV-HKU1, HCoV-229E and HCoV-NL63).

HRV, human rhinoviruses; MJS, Modified Jackson Score. 


\section{Post hoc analysis}

There was weak evidence that the difference in the primary outcome between treatment groups varied depending on CoV status, $p$ interaction $=0.067$. Participants in the $\mathrm{rNHF}$ group with a nasopharyngeal specimen PCR positive for a $\mathrm{CoV}$, did worse than those in the 'sham' group (table 2).

\section{Adverse events}

AEs are listed in online supplemental tables 12 and 13. There was one hospital admission due to appendicitis in the rNHF group. There were no serious AEs related to the study treatments.

\section{DISCUSSION}

This RCT found no evidence that $100 \%$ humidified air heated to $41^{\circ} \mathrm{C}$ delivered at $35 \mathrm{~L} / \mathrm{min}$ to the upper airway via nasal prongs ( $\mathrm{rNHF}$ ), reduces common cold symptom severity or duration compared with 'sham' rhinothermy.

Study strengths include the investigator supervised first treatment which ensured the first dose was received, and the use of a sham intervention. The sham intervention reduced any potential device-related effect, as medical devices may have an enhanced placebo effect. ${ }^{25} 26$

There are a number of potential explanations for the lack of efficacy of rNHF. The first is that the nasopharyngeal temperature achieved during rNHF treatment was not high enough to inhibit viral replication, either because the temperature of the inspired gas in the nasopharynx was cooler than the $41^{\circ} \mathrm{C}$ delivered by the device, or a temperature higher than $41^{\circ} \mathrm{C}$ is required to inhibit viral replication. The majority of temperature sensitivity ( $t s$ ) data for common cold viruses relate to HRV and have demonstrated $t s$ in vitro at $37^{\circ} \mathrm{C}-45^{\circ} \mathrm{C},{ }^{8-10}$ although some HRV strains have been shown to replicate equally well or better at $37^{\circ} \mathrm{C} .{ }^{27-30}$ The variability among HRV strains and limited $t s$ data for other common cold viruses, created a challenge when selecting an optimal temperature for the rhinothermy regimen. For example, SARS-CoV and MERS-CoV, members of the genus $\beta$-coronaviruses of the coronaviridae family, lose infectivity following exposure to temperatures exceeding $56^{\circ} \mathrm{C},{ }^{31}{ }^{32}$ however, there is little $t s$ data for coronaviruses that cause the common cold.

There is clinical evidence that temperatures $>41^{\circ} \mathrm{C}$ may be required to elicit a benefit in vivo, based on studies which have shown improvement in common cold symptoms with delivery of $\mathrm{HHA}$ at $42^{\circ} \mathrm{C}-44^{\circ} \mathrm{C}$ for cumulative durations of 20-90 min. ${ }^{1416}$ However, there is report of minor nasal mucosal burns occurring at $43^{\circ} \mathrm{C}$. ${ }^{7}$

Face mask delivery of $\mathrm{HHA}$ at $37^{\circ} \mathrm{C}$ has been shown to reduce allergen-induced congestion and nasal secretions. ${ }^{13}$ Regulatory guidance for heated humidifiers recommends an upper temperature limit of $42^{\circ} \mathrm{C}$ for inspired air. ${ }^{33}$ As such we selected $41^{\circ} \mathrm{C}$ to ensure that airway temperature did not exceed $42^{\circ} \mathrm{C}$, but was still high enough to potentially inhibit replication of the most frequent causative virus HRV, and might also improve nasal symptoms.
A second potential explanation is that treatment was commenced too late after symptom onset to obtain an effect, although the results of this study found no difference in the primary outcome for those who started treatment within 24 hours and those who started $\geq 24$ hours but $\leq 48$ hours from symptom onset. Nevertheless, this concern remains based on the in vitro study by Conti et al which noted that HRV replication was inhibited by 20 min exposure to a temperature of $45^{\circ} \mathrm{C}$, and that the greatest effect occurred at 6 hours postinfection, with a $99 \%$ reduction in virus yield compared with the control. ${ }^{8}$ In contrast, this temperature did not change viral protein synthesis at nine and 11 hours post infection, leading to the hypothesis that the antiviral effect of high temperature was a posttranslational event. ${ }^{8}$ These results highlight the potential importance of treatment start time, and suggest that earlier start times could be required for optimal impact on viral replication, although the narrow time-window poses practical challenges.

This study was completed prior to the emergence of $\beta$-coronavirus SARS-CoV-2 (COVID-19). However, 18\% of enrolled participants in this study were positive for other coronaviruses $(48 \%$ of which were $\beta$-coronaviruses, HCoV-HKU1 and HCoV-OC43). Therefore, a post hoc analysis testing for an interaction between $\mathrm{CoV}$ status and the primary outcome was considered relevant. This analysis provided weak evidence that the rNHF group with a nasopharyngeal specimen PCR positive for a $\mathrm{CoV}$ did worse than those in the 'sham' regimen. As such, these findings would not support the use of rhinothermy in reducing symptom severity in SARS-CoV-2. Moreover, as yet there is no available $t s$ data for SARS-CoV-2, but if similar to the temperatures of least $56^{\circ} \mathrm{C}$ required to reduce infectivity in SARS-CoV and MERS-CoV, ${ }^{31}{ }^{32}$ it would not be safe to deliver as rhinothermy. Conversely, there is scope to investigate rNHF in the treatment of influenza. A positive point-of-care test for influenza was an exclusion criterion for this study and therefore the results cannot be assumed to be generalisable to patients with influenza. Influenza often produces symptoms similar to other viral URTIs but is one of the most important public health problems around the world, accounting for up to five million severe illnesses and 500000 deaths each year. ${ }^{34}$ Viral replication and the subsequent host inflammatory response play key roles in the pathogenesis of influenza infection ${ }^{35}$ and many in vitro studies have demonstrated a reduction in virus replication with exposure to temperatures of $39^{\circ} \mathrm{C}-41^{\circ} \mathrm{C}$ for a number of strains of influenza $\mathrm{A}$ and $\mathrm{C}$ virus. ${ }^{36-38}$ Furthermore, disease severity and mortality associated with avian influenza A (H5N1) virus, have been linked to high pharyngeal viral loads. ${ }^{35}$

\section{Limitations}

There are several study limitations. First, due to recruitment measures the sample population consisted predominantly of university students, which reduces the overall generalisability of the results to younger adults. Second, due to the nature of the intervention it was not possible 
to use a double-blind design; however, the single-blind design with a sham intervention arm reduces participant bias. Third, although there was no evidence of a difference in adherence between treatments, the accuracy of adherence data is limited. It was determined by review of downloaded device data which shows when and for how long the device was turned on and delivering HHA, but cannot confirm delivery to the participant. Resultantly, undetected variation in adherence may have influenced the study outcome.

\section{CONCLUSION}

This well-powered, single-blind RCT does not provide evidence that 5 days of rNHF $(100 \%$ humidified air heated to $41^{\circ} \mathrm{C}$ delivered at $35 \mathrm{~L} / \mathrm{min}$ for 2 hours daily) reduces common cold symptom severity or duration. However, investigation of rNHF in the treatment of influenza is warranted.

Acknowledgements The research was sponsored and funded by Fisher \& Paykel Healthcare (Auckland, New Zealand). We thank all those who supported study staff, including Tony Mallon, Carla Mclnnes, Joanna Read, Alex Semprini, Alison Pritchard, Kathryn Fernando, Judith Riley, Allie Eathorne, Julie Jones, Christina Baggott, Luke Barker, Jo Hardy and Cilein Kearns.

Contributors GB wrote this manuscript as well as the HDEC approved study protocol and study materials with input from IB and JF. She also produced the REDCap database for data collection with input from NS. RB is the guarantor of this study. RB, IB and JF helped design the study. RB and IB directed the project. MW designed the randomisation schedule and performed the statistical analysis. MD and LJ advised on collection and laboratory analysis of nasopharyngeal specimens. $\mathrm{JH}, \mathrm{IK}, \mathrm{MvdB}$, IM and NK were study investigators.

Funding This work was funded by Fisher \& Paykel Healthcare (Auckland, New Zealand) (FPH), MRINZ/17/05. FPH also provided the rhinothermy and myAIRV02 ('sham' rhinothermy) devices and associated consumables.

Disclaimer FPH had no involvement in data collection, analysis or interpretation, or the preparation of this manuscript.

Competing interests None declared.

Patient consent for publication Not applicable.

Ethics approval The New Zealand Southern Health and Disability Ethics Committee (HDEC) provided ethical approval and all participants provided written, informed consent for participation in the study.

Provenance and peer review Not commissioned; externally peer reviewed.

Data availability statement All data relevant to the study are included in the article or uploaded as online supplemental information. This manuscript reports all relevant study data in the article or supplementary information and includes deidentified participant data.

Supplemental material This content has been supplied by the author(s). It has not been vetted by BMJ Publishing Group Limited (BMJ) and may not have been peer-reviewed. Any opinions or recommendations discussed are solely those of the author(s) and are not endorsed by BMJ. BMJ disclaims all liability and responsibility arising from any reliance placed on the content. Where the content includes any translated material, BMJ does not warrant the accuracy and reliability of the translations (including but not limited to local regulations, clinical guidelines, terminology, drug names and drug dosages), and is not responsible for any error and/or omissions arising from translation and adaptation or otherwise.

Open access This is an open access article distributed in accordance with the Creative Commons Attribution Non Commercial (CC BY-NC 4.0) license, which permits others to distribute, remix, adapt, build upon this work non-commercially, and license their derivative works on different terms, provided the original work is properly cited, appropriate credit is given, any changes made indicated, and the use is non-commercial. See: http://creativecommons.org/licenses/by-nc/4.0/.
ORCID iDs

Grace Bird http://orcid.org/0000-0002-3761-2778

Irene Braithwaite http://orcid.org/0000-0001-5327-3027

Nethmi Kearns http://orcid.org/0000-0002-3188-991X

Richard Beasley http://orcid.org/0000-0003-0337-406X

\section{REFERENCES}

1 Singh M, Singh M, Jaiswal N, et al. Heated, humidified air for the common cold. Cochrane Database Syst Rev 2017;8:CD001728.

2 Nicholson KG, Kent J, Ireland DC. Respiratory viruses and exacerbations of asthma in adults. BMJ 1993;307:982-6.

3 Hurst JR, Donaldson GC, Wilkinson TMA, et al. Epidemiological relationships between the common cold and exacerbation frequency in COPD. Eur Respir J 2005;26:846-52.

4 Fendrick AM, Monto AS, Nightengale B, et al. The economic burden of non-influenza-related viral respiratory tract infection in the United States. Arch Intern Med 2003;163:487-94.

5 Allan GM, Arroll B. Prevention and treatment of the common cold: making sense of the evidence. CMAJ 2014;186:190-9.

6 Foxman EF, Storer JA, Fitzgerald ME, et al. Temperature-Dependent innate defense against the common cold virus limits viral replication at warm temperature in mouse airway cells. Proc Natl Acad Sci U S A 2015;112:827-32.

7 Forstall GJ, Macknin ML, Yen-Lieberman BR, et al. Effect of inhaling heated vapor on symptoms of the common cold. JAMA 1994;271:1109-11.

8 Conti C, De Marco A, Mastromarino P, et al. Antiviral effect of hyperthermic treatment in rhinovirus infection. Antimicrob Agents Chemother 1999;43:822-9.

9 Stott EJ, Heath GF. Factors affecting the growth of rhinovirus 2 in suspension cultures of L 132 cells. J Gen Virol 1970;6:15-24.

10 Killington RA, Stott EJ, Lee D. The effect of temperature on the synthesis of rhinovirus type 2 RNA. J Gen Virol 1977;36:403-11.

11 Downing JF, Taylor MW, Wei KM. In vivo hyperthermia enhances plasma antiviral activity and stimulates peripheral lymphocytes for increased synthesis of interferon- $\gamma$. J Interferon Res 1987.

12 Zhu L-li, Gao X-H, Qi R, et al. Local hyperthermia could induce antiviral activity by endogenous interferon-dependent pathway in condyloma acuminata. Antiviral Res 2010;88:187-92.

13 Baroody FM, Assanasen P, Chung J, et al. Hot, humid air partially inhibits the nasal response to allergen provocation. Arch Otolaryngol Head Neck Surg 2000;126:749.

14 Tyrrell D, Barrow I, Arthur J. Local hyperthermia benefits natural and experimental common colds. BMJ 1989;298:1280-3.

15 Macknin ML, Mathew S, Medendorp SV. Effect of inhaling heated vapor on symptoms of the common cold. JAMA 1990;264:989-91.

16 Ophir D, Elad Y. Effects of steam inhalation on nasal patency and nasal symptoms in patients with the common cold. Am J Otolaryngol 1987;8:149-53.

17 Hendley JO, Abbott RD, Beasley PP, et al. Effect of inhalation of hot humidified air on experimental rhinovirus infection. JAMA 1994;271:1112-3.

18 Hei Svande, McKinstry S, Bardsley G, et al. Randomised controlled trial of rhinothermy for treatment of the common cold: a feasibility study. BMJ Open 2018;8:e019350.

19 Bird G, Braithwaite I, Harper J, et al. Protocol for a randomised, single-blind, two-arm, parallel-group controlled trial of the efficacy of rhinothermy delivered by nasal high flow therapy in the treatment of the common cold. BMJ Open 2019;9:e028098.

20 Dowling HF, Jackson GG, Spiesman IG, et al. Transmission of the common cold to volunteers under controlled conditions. III. The effect of chilling of the subjects upon susceptibility. Am J Hyg 1958;68:59-65.

21 Gwaltney JM, Moskalski PB, Hendley JO. Interruption of experimental rhinovirus transmission. J Infect Dis 1980;142:811-5.

22 Salez N, Nougairede A, Ninove L, et al. Xpert flu for point-of-care diagnosis of human influenza in industrialized countries. Expert Rev Mol Diagn 2014;14:411-8.

23 Harris PA, Taylor R, Thielke R, et al. Research electronic data capture (REDCap)--a metadata-driven methodology and workflow process for providing translational research informatics support. J Biomed Inform 2009;42:377-81.

24 Schulz KF, Altman DG, CONSORT MD. Consort 2010 statement. Obstet Gynecol 2010;2010:115.

25 Kaptchuk TJ, Goldman P, Stone DA, et al. Do medical devices have enhanced placebo effects? J Clin Epidemiol 2000;53:786-92.

26 Kaptchuk TJ, Stason WB, Davis RB, et al. Sham device V inert pill: randomised controlled trial of two placebo treatments. BMJ 2006;332:391-7. 
27 Papadopoulos NG, Sanderson G, Hunter J, et al. Rhinoviruses replicate effectively at lower airway temperatures. J Med Virol 1999;58:100-4

28 Tapparel C, Sobo K, Constant S, et al. Growth and characterization of different human rhinovirus $\mathrm{C}$ types in three-dimensional human airway epithelia reconstituted in vitro. Virology 2013;446:1-8.

29 Ashraf S, Brockman-Schneider R, Bochkov YA, et al. Biological characteristics and propagation of human rhinovirus- $C$ in differentiated sinus epithelial cells. Virology 2013;436:143-9.

30 Papadopoulos NG, Bates PJ, Bardin PG, et al. Rhinoviruses infect the lower airways. J Infect Dis 2000;181:1875-84. doi:10.1086/315513

31 Duan S-M, Zhao X-S, Wen R-F, et al. Stability of SARS coronavirus in human specimens and environment and its sensitivity to heating and UV irradiation. Biomed Environ Sci 2003;16:246-55.

32 Leclercq I, Batéjat C, Burguière AM, et al. Heat inactivation of the middle East respiratory. Influenza Other Respir Viruses 2014;8:585-6.

33 Government guidance document issued by 'U.S. Food and Drug Administration (FDA)'. Unique ID: HHS-0910-1991-F-8697.
Available from U.S. Dept. of Health \& Human Services online guidance portal, 1991. Available: https://www.hhs.gov/guidance/ document/heated-humidifier-review-guidance [Accessed 29 May 2020].

34 World Health Organisation. Influenza (seasonal) fact sheet No. 211. Media Cent, 2014.

35 de Jong MD, Simmons CP, Thanh TT, et al. Fatal outcome of human influenza $\mathrm{A}(\mathrm{H} 5 \mathrm{~N} 1)$ is associated with high viral load and hypercytokinemia. Nat Med 2006;12:1203-7.

36 Yamaya M, Nishimura $\mathrm{H}$, Lusamba Kalonji N, et al. Effects of high temperature on pandemic and seasonal human influenza viral replication and infection-induced damage in primary human tracheal epithelial cell cultures. Heliyon 2019;5:e01149.

37 Chu CM, Tian SF, Ren GF, et al. Occurrence of temperature-sensitive influenza A viruses in nature. J Virol 1982;41:353-9.

38 Takashita E, Muraki Y, Sugawara K, et al. Intrinsic temperature sensitivity of influenza $\mathrm{C}$ virus hemagglutinin-esterase-fusion protein. J Virol 2012;86:13108-11. 